\title{
Bafilomycin analogue site-specifically fluorinated at the pharmacophore macrolactone ring has potent vacuolar-type ATPase inhibitory activity
}

\author{
Hiroshi Tsuchikawa $^{\mathrm{a}}$, Tatsuru Hayashi ${ }^{\mathrm{a}}$, Hajime Shibata ${ }^{\mathrm{a}, \mathrm{b}}$, Michio Murata $^{\mathrm{a}, \mathrm{b}}{ }_{*}$, Yoko Nagumo $^{\mathrm{c}}$ and \\ Takeo Usui ${ }^{\mathrm{c}}$ \\ ${ }^{a}$ Graduate School of Science, Osaka University, 1-1 Machikaneyama, Toyonaka, Osaka 560-0043, Japan \\ ${ }^{b}$ ERATO, Lipid Active Structure Project, Japan Science and Technology Agency, 1-1 Machikaneyama, Toyonaka, Osaka 560-0043, Japan \\ ${ }^{c}$ Faculty of Life and Environmental Sciences, University of Tsukuba, Tennodai, Tsukuba, Ibaraki 305-8572, Japan
}

\section{ARTICLE INFO}

Article history:

Received

Received in revised form

Accepted

Available online

\section{Keywords:}

fluorine-label

chemical synthesis

V-ATPase

bafilomycin

conformational analysis

\section{ABSTRACT}

Based on previously reported structure-activity relationships, an analogue of bafilomycin $A_{1}$ with a site-specific fluorine label at the $\mathrm{C} 2$ position was designed and efficiently synthesized. The fluorinated compound exhibited potent vacuolar-type ATPase (V-ATPase) inhibitory activity, comparable to that of the natural product, representing the first example of highly bioactive analogues with a modified macrolactone core from the plecomacrolide family compounds.

2009 Elsevier Ltd. All rights reserved.
A vacuolar-type ATPase (V-ATPase) is an ATP-driven proton pump occurring in eukaryotic cells. V-ATPase acts upon acidification of endomembrane organelles such as lysosomes, endosomes and Golgi apparatus to regulate protein degradation and transport. ${ }^{1}$ Subtypes of V-ATPase are also distributed in the plasma membranes of various cells, including osteoclasts, renal intercalated cells, and cancer cells, and are correspondingly deeply involved in bone resorption, $\mathrm{pH}$ homeostasis and cell growth. ${ }^{1-4}$ Consequently, specific inhibitors of V-ATPase have received significant attention as useful tools for functional analysis, and also as drug candidates. For example, it has been suggested that suppression of V-ATPase activity induces the apoptotic death of cancer cells. ${ }^{5,6}$

One of the most potent and specific V-ATPase inhibitors, bafilomycin $\mathrm{A}_{1}$ (Baf, 1, Scheme 1), was first isolated from Streptomyces griseus ssp. sulphurus. ${ }^{7}$ Although it has been widely utilized as a diagnostic agent for V-ATPase-implicated biological events, the molecular mechanism of action is not fully elucidated; the binding site has been deduced to be the subunit $\mathrm{c}$ ring of the transmembranous $\mathrm{V}_{\mathrm{o}}$ domain. ${ }^{8,9}$

To elucidate the exact binding site for attachment of Baf to VATPase, we utilized structural analysis using ${ }^{13} \mathrm{C}\left\{{ }^{19} \mathrm{~F}\right\}$ REDOR, ${ }^{10}$ which is a distance measurement solid-state NMR technique often used for complicated non-crystalline systems such as membrane proteins. ${ }^{11}$ Preparation of a bioactive fluorine-labeled

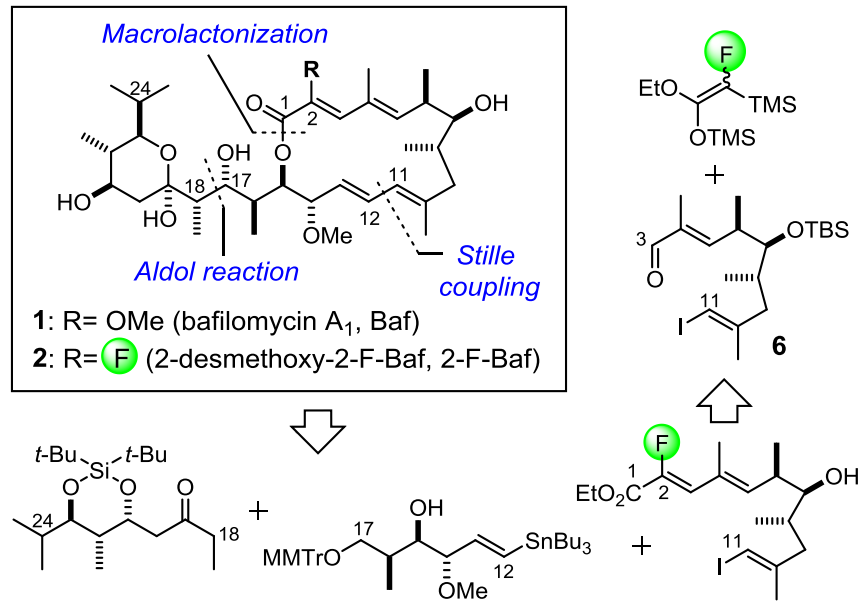

C18-C24 segment $3 \quad$ C12-C17 segment 4

C1-C11 segment 5

Scheme 1. Retrosynthesis of 2-F-Baf

derivative is essential as the first step of this strategy; we recently successfully synthesized 24,24-didesmethyl-24-F $-\mathrm{Baf}$ (24-F$\mathrm{Baf}$ ) possessing a $\mathrm{CF}_{3}$ group at the $\mathrm{C} 23$ position instead of the $i$ propyl group. This structure was carefully designed based on consideration of previously reported structure-activity relationship (SAR) data. ${ }^{12}$ As anticipated we confirmed the potent V-ATPase inhibitory activity of 24-F-Baf. ${ }^{13}$ Another objective for the synthesis of fluorine-labeled Baf is to elucidate

* Corresponding author. Tel.: +81-6-6850-5774; fax: +81-6-6850-5774; e-mail: murata@ chem.sci.osaka-u.ac.jp 
the exact conformation of Baf in the V-ATPase bound form since knowledge of the active structure of a specific inhibitor upon binding to a potential drug target protein generally provides important information for drug development. The significance of the macrolide conformation of Baf to the overall binding structure could be determined by using a site-specifically fluorinated Baf analogue at this moiety. However the potential perturbation induced by fluorine substitution ${ }^{14}$ was of particular concern since the macrolactone ring was thought to be the pharmacophore for V-ATPase binding. Previous SAR experiments demonstrated that any modifications on the macrolactone resulted in loss of activity. For example, opening of the lactone ring, oxidation of the 7-hydroxy group to the ketone, and even desmethylation of the two methyl groups at the C6 and C8 positions remarkably diminished the activity. ${ }^{12,13 b}$

Considering the previous results, we designed and synthesized a novel fluorine-labeled Baf analogue modified at the macrolactone backbone; this analogue exhibited V-ATPase inhibitory activity comparable to that of the native structure. Compound 2 (2-F-Baf, 2) is the first analogue with the modified macrolactone that possesses potent bioactivity.

In selecting the position for fluorine substitution, we first chose the hydroxy or methoxy group to minimize perturbation of the polarity. Among the three possible positions, the 7-hydroxy group and 14-methoxy group were ruled out because of the known biological importance and the expected instability, respectively. Hence, the 2-F-Baf derivative (2-F-Baf, 2) was selected as a synthesis target; this moiety was expected to be easier to synthesize despite concerns about the effect of fluorine in destabilizing the surrounding dienoate moiety (Scheme 1). The strategy involved the convergent synthetic method estapblished for synthesis of 24-F-Baf from three key segments via the Stille coupling, macrolactonization, and diastereoselective aldol reactions. ${ }^{13}$ For synthesis of the C18-C24 segment, 3, which was already reported by two groups, ${ }^{15}$ we examined a new route by modifying our scheme for synthesis of the $\mathrm{CF}_{3}-\mathrm{C} 18-\mathrm{C} 24$ segment to improve the efficiency. ${ }^{13}$ The 2-F-labeled C1-C11 segment, $\mathbf{5}$, could be synthesized from the known aldehyde $\mathbf{6}$ via Z-selective fluoroolefination.

Initially, the C18-C24 segment, 3, was prepared by starting from the known Weinreb amide $7^{16}$ as shown in Scheme 2. After
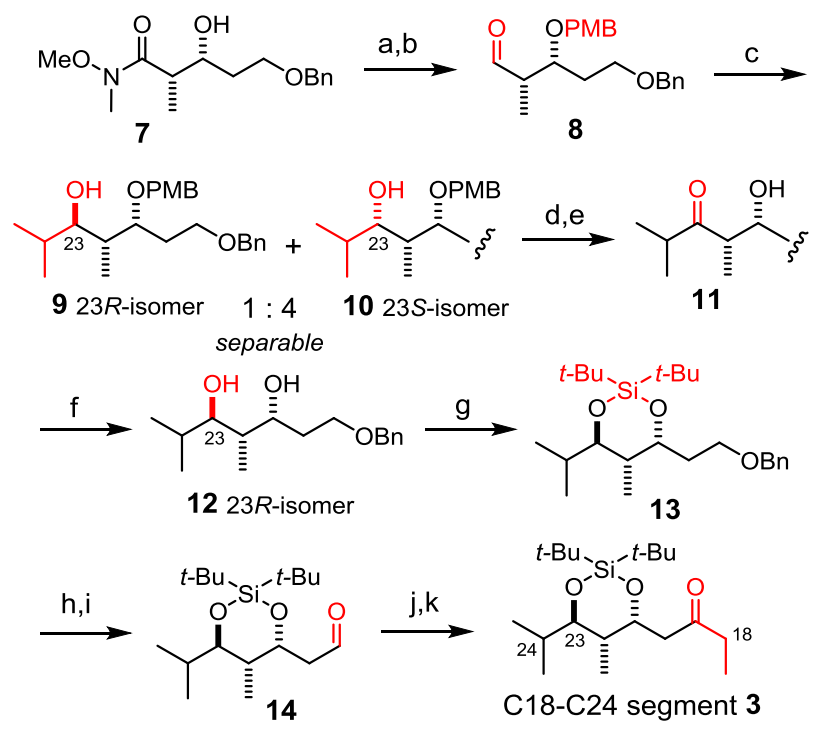

Scheme 2. Synthesis of the C18-C24 segment 3

Reagents and conditions: a) $\mathrm{PMBOCNHCCl}, \mathrm{Sc}(\mathrm{OTf})_{3}$, toluene, rt, $85 \%$; b) DIBAL, $\mathrm{CH}_{2} \mathrm{Cl}_{2},-78^{\circ} \mathrm{C}, 92 \%$; c) $i$-PrMgBr, THF, $0{ }^{\circ} \mathrm{C}$, $81 \%$; d) AZADOL, TBAB, $\mathrm{NaClO} \cdot 5 \mathrm{H}_{2} \mathrm{O}, \mathrm{KBr}, \mathrm{CH}_{2} \mathrm{Cl}_{2}, \mathrm{NaHCO}_{3}$ aq, $0{ }^{\circ} \mathrm{C}, 99 \%$; e) DDQ, $\mathrm{CH}_{2} \mathrm{Cl}_{2}$, PBS buffer (pH 7.0), rt, 74\%; f) $\mathrm{Me}_{4} \mathrm{NBH}(\mathrm{OAc})_{3}, \mathrm{AcOH}, \mathrm{rt}, 79 \%$ and $10 \% 23 \mathrm{~S}$-isomer; g) $(t$ $\mathrm{Bu})_{2} \mathrm{Si}(\mathrm{OTf})_{2}$, 2,6-lutidine, DMF, rt, $85 \%$; h) $\mathrm{H}_{2}$, Pd black, EtOH, rt, $68 \%$; i) Dess-Martin periodinane, $\mathrm{NaHCO}_{3}, \mathrm{CH}_{2} \mathrm{Cl}_{2}, \mathrm{rt}, 86 \%$; j) EtMgBr, THF, rt, 99\%; k) Dess-Martin periodinane, $\mathrm{NaHCO}_{3}$, $\mathrm{CH}_{2} \mathrm{Cl}_{2}, \mathrm{rt}, 92 \%$

several attempts at direct alkylation to $7,{ }^{17}$ it was found that transformation to the aldehyde $\mathbf{8}$ and the subsequent addition of isopropyl magnesium bromide afforded the isopropylated alcohols $\mathbf{9}$ and $\mathbf{1 0}$ as 1:4 diastereomer mixtures. This undesired stereoselectivity could be explained by Felkin-Ahn model applied to $\alpha$-chiral aldehydes. The undesired $23 S$-epimer 10 was separately oxidized to the ketone, ${ }^{18}$ and removal of the $p$ methoxybenzyl (PMB) group yielded the $\beta$-hydroxyketone 11, which was followed by 1,3-anti-selective reduction reported by Evans to furnish the desired $23 R$-isomer $\mathbf{1 2}$ with good

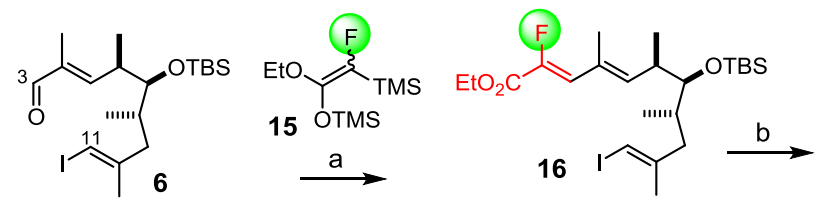<smiles>CCOC(=O)CC(C)=CC(C)=CC(C)C(O)[C@@H](C)CC(C)=C[I+]</smiles>

C1-C11 segment 5

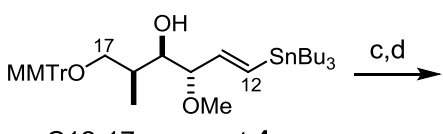

C12-17 segment 4

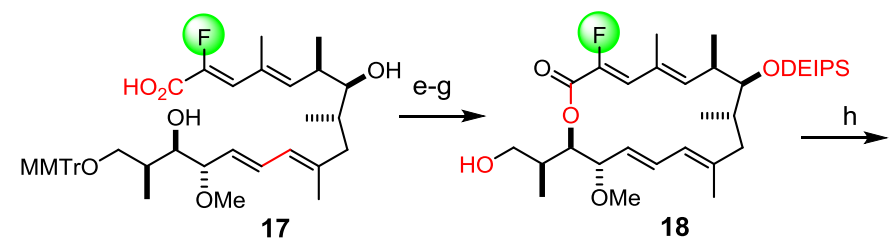

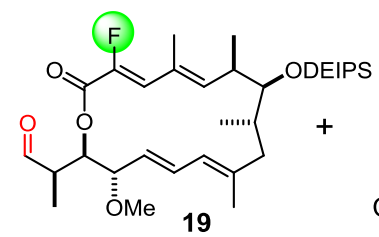

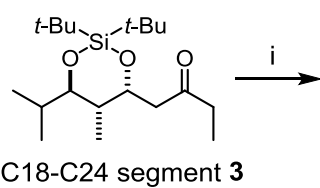

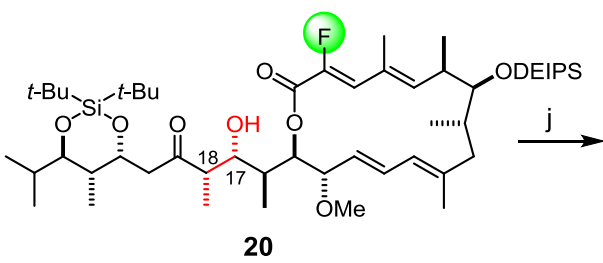

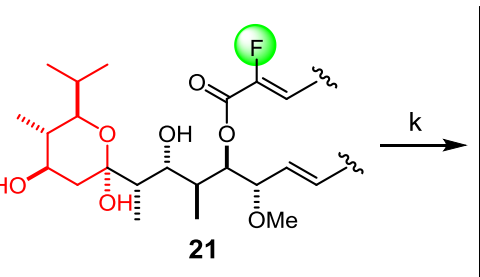

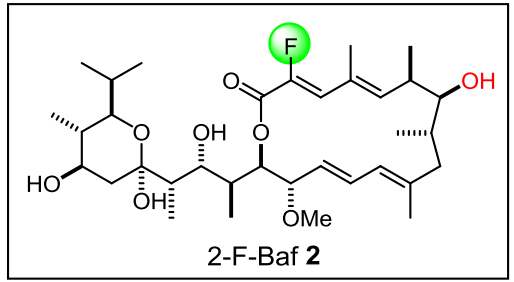

Scheme 3. Synthesis of 2-F-Baf 2

Reagents and conditions: a) 15, $n$ - $\mathrm{Bu}_{4} \mathrm{NOAc}, \mathrm{CH}_{2} \mathrm{Cl}_{2}, \mathrm{rt}$; b) TBAF, THF, rt, $48 \%$ (2 steps); c) $\left[\mathrm{Pd}_{2}(\mathrm{dba})_{3}\right] \cdot \mathrm{CHCl}_{3}, \mathrm{Ph}_{3} \mathrm{As}, \mathrm{LiCl}_{\mathrm{NMP}} \mathrm{Nt}$, $63 \%$; d) $\mathrm{KOH}$, dioxane, $80^{\circ} \mathrm{C}$; e) 2,4,6-trichlorobenzoyl chloride, $i$ - $\mathrm{Pr}_{2} \mathrm{NEt}$, toluene, rt, then diluted with toluene, DMAP, $34 \%$ (2 steps); f) DEIPSOTf, 2,6-lutidine, $\mathrm{CH}_{2} \mathrm{Cl}_{2}, 0{ }^{\circ} \mathrm{C}, 90 \%$; g) PPTS, THF, MeOH, rt, $83 \%$; h) $(\mathrm{COCl})_{2}, \mathrm{DMSO}, \mathrm{Et}_{3} \mathrm{~N}, \mathrm{CH}_{2} \mathrm{Cl}_{2},-78{ }^{\circ} \mathrm{C}$ to $0{ }^{\circ} \mathrm{C}$; i) 3 , $\mathrm{PhBCl}_{2}, i-\mathrm{Pr}_{2} \mathrm{NEt}, \mathrm{CH}_{2} \mathrm{Cl}_{2},-78{ }^{\circ} \mathrm{C}, 60 \%$ (2 steps); j) $18 \%$ HF.Py, THF, rt, 67\%; k) TBAF, AcOH, THF, rt, $48 \%$ 
selectivity. ${ }^{19}$ After cyclic silyl protection of the diols and silica gel purification, the desired silyl ether $\mathbf{1 3}$ was obtained in $85 \%$ yield, followed by a conventional sequence in four steps to afford the $\mathrm{C} 18-\mathrm{C} 24$ segment, 3 . The overall steps were shortened and modification of the $\mathrm{C} 23$ substituent was more facile than in previous reports. $^{15}$

Subsequently, synthesis of the 2-fluorinated C1-C11 segment, $\mathbf{5}$, and the ensuing coupling reactions leading to 2-F-Baf, $\mathbf{2}$, were performed as shown in Scheme 3. At first, the fluoroolefination of aldehyde 6, which was synthesized as outlined in our previous report, ${ }^{13}$ was examined using fluoro(trimethylsilyl)ketene ethyl trimethylsilyl acetal 15 (Z:E = 1:1) in the presence of a catalytic amount of $n$ - $\mathrm{Bu}_{4} \mathrm{NOAc}$ as a Lewis base according to Michida's procedure. $^{20}$ The reaction proceeded smoothly to afford the desired (Z)- $\alpha$-fluoroacrylate product selectively and the subsequent deprotection of $t$-butyldimethylsilyl (TBS) ether gave the C1-C11 segment, 5 in $48 \%$ yield in two steps. The Stille coupling reaction with the separately prepared $\mathrm{C} 12-\mathrm{C} 17$ segment, $4^{13 b}$ and hydrolysis of the ethyl ester furnished the carboxylic acid 17; this process was followed by macrolactonization under Yamaguchi conditions ${ }^{21}$ to successfully furnish the fluorinecontaining macrolactone in a similar yield to that obtained with the non-fluorinated seco acid. ${ }^{13}$ Protection of the secondary alcohol with a diethylisopropylsilyl (DEIPS) group via a previously optimized process ${ }^{15 a}$ and selective removal of the monomethoxytrityl (MMTr) group with pyridinium $p$ toluenesulfonate (PPTS) furnished the primary alcohol 18 in $83 \%$ yield despite the expected lability of the fluorinated dienoate moiety under acidic conditions. After oxidation to aldehyde 19, the $(E)$-boron enolate generated from ketone $\mathbf{3}$ was added and stirred at $-78{ }^{\circ} \mathrm{C}$ for three hours to give the desired hydroxyketone 20 with excellent stereoselectivity in $60 \%$ yield, ${ }^{22}$ which was comparable to the data for natural Baf synthesis. ${ }^{15 a, 23}$ Finally, deprotection of the two silyl groups was performed by using carefully tuned conditions, including the use of $18 \%$ $\mathrm{HF} \bullet$ pyridine and TBAF with $\mathrm{AcOH}$, leading to completion of the synthesis of 2-F-Baf. ${ }^{24}$

To evaluate the biological activity of 2-F-Baf, 2, the inhibitory effect of V-ATPase on the acidification of acidic organelles was examined using HeLa cells (Figure 1). ${ }^{13}$ The control cells exhibited the red fluorescence of acidic vesicles, which were acidified by properly functioning V-ATPase. In contrast, treatment with 2-F-Baf, 2 markedly reduced the red fluorescence to a similar extent to that achieved with Baf, $\mathbf{1}$, which implied that 2-F-Baf, 2 possessed potent V-ATPase inhibitory activity, comparable to that of the natural product. To evaluate the inhibition potency of $\mathbf{2}$, the inhibitory effect on V-ATPase activity was evaluated based on quantification of the inorganic phosphate produced by ATP hydrolysis (Table 1). ${ }^{13,25}$ The results demonstrated that 2-F-Baf, 2, inhibited V-ATPase function as potently as natural $\mathrm{Baf}, \mathbf{1},\left(\mathrm{IC}_{50}=5.3\right.$ and $4.3 \mathrm{nM}$, respectively), indicating that fluorine substitution at the $\mathrm{C} 2$ position of Baf induced no perturbation effect.

\section{2 hour treatment against HeLa cells}

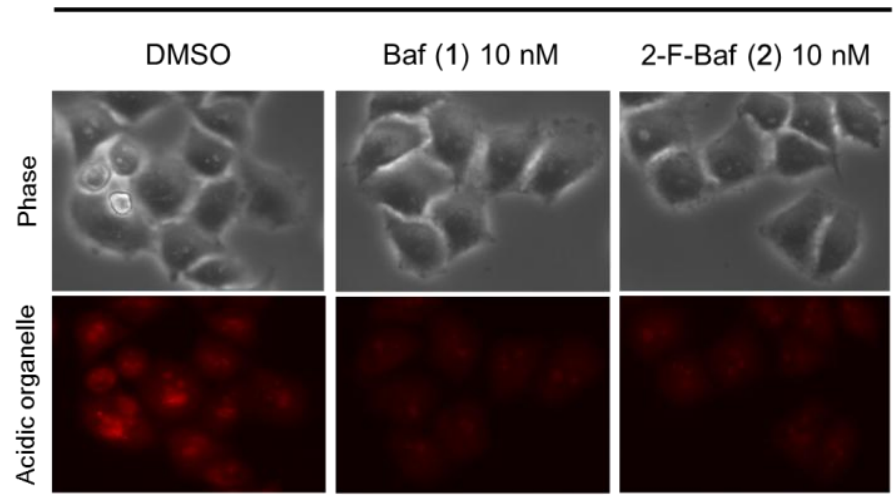

Figure 1. Effect of 2-F-Baf on acridine orange stain of HeLa cells.
Table 1. V-ATPase inhibition of budding yeast

\begin{tabular}{cc}
\hline & $\mathrm{IC}_{50}(\mathrm{nM})$ \\
\hline Baf 1 & 4.3 \\
2-F-Baf 2 & 5.3
\end{tabular}

After confirming the potent activity of 2-F-Baf, we next examined whether the analogue maintained enough of the structural features of Baf to be used for accurate conformational analysis in solid-state NMR by comparing their structures in solution. The ${ }^{1} \mathrm{H}$ NMR data of $\mathbf{2}$ were compared with those of $\mathbf{1}$ as shown in Figure 2. Most of the ${ }^{1} \mathrm{H}$ chemical shifts of these two species were similar $(\Delta \delta<0.05 \mathrm{ppm})$, except for those of the protons close to the fluorine atom and susceptible hydroxy protons (H3, H5,17-OH, 19-OH) (see Supporting Information for detailed data). Moreover, all coupling constants of the protons on the ring shown in Figure 2A were consistent with those of Baf, and NOE correlations attributed to $\mathrm{H} 3 / \mathrm{H} 5$ and $\mathrm{H} 8 / \mathrm{H} 11$, characteristic to Baf, were observed (Figure 2B). These observations suggested that the entire conformation of the macrolactone ring is virtually the same as that of Baf. To confirm the conformation, a detailed structural analysis was performed using Macromodel with some restrictions derived from NMR experiments (Figure 2B) (see Supporting Information for detailed data). The superimposed structures clearly showed that 2-F-Baf and Baf have a similar conformation in the macrolactone moiety, especially in the direction of the 7-hydroxy group; this conformation was largely altered in non-active analogues such as the 6,8-desmethylated derivative. ${ }^{13 \mathrm{~b}}$ These results suggest that 2-

(A)
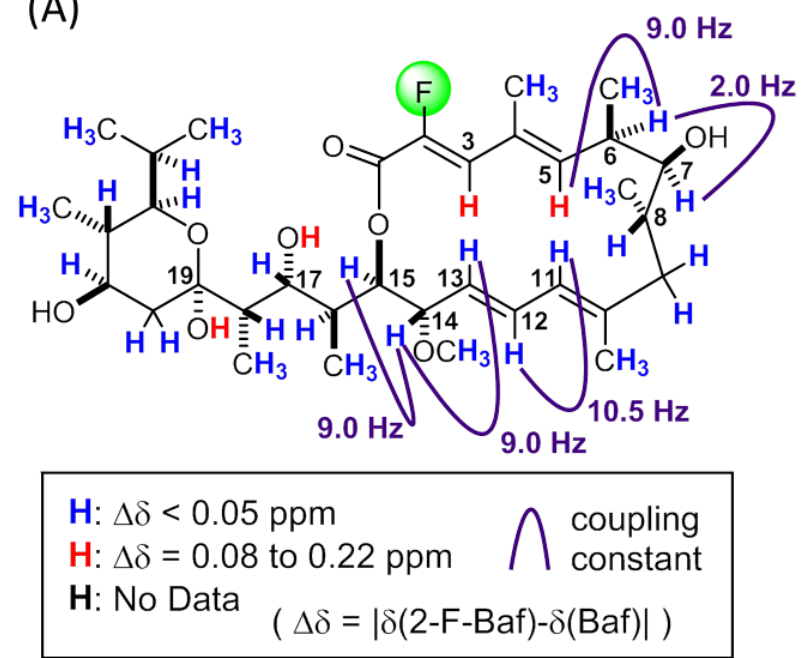

(B)

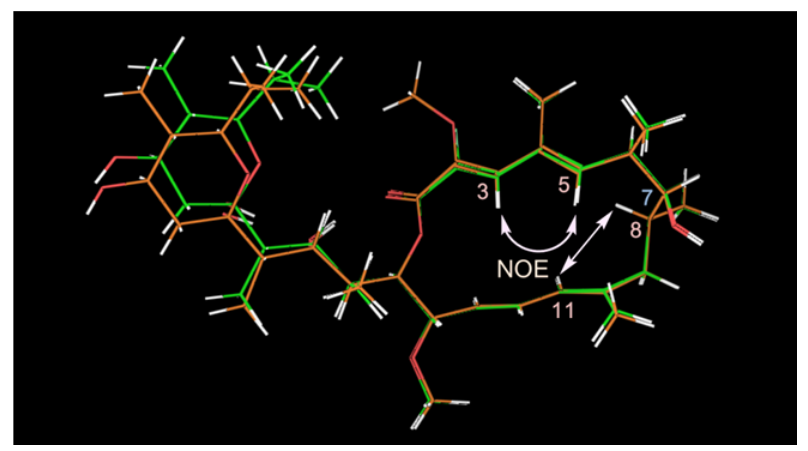

Figure 2. (A) Differences of ${ }^{1} \mathrm{H}$ NMR chemical shifts between 2F-Baf 2 and Baf 1 and observed coupling constants in $\mathrm{CDCl}_{3}$ (B) Lowest-energy conformation of Baf (orange) and 2-F-Baf (green) and experimentaly observed NOE correlations of them 
F-Baf retains not only the V-ATPase activity but also the conformation of natural $\mathrm{Baf}$ in $\mathrm{CDCl}_{3}$ solution.

It is recognized that there must be some differences between the conformation in solution and the active $3 \mathrm{D}$ structure upon binding to V-ATPase in the membrane, because the former is largely influendce by intramolecular hydrogen bonding, whereas, the latter is potentially affected by interaction with protein. Nevertheless, we deduce that there may be some correlations since Baf is thought to bind to the hydrophobic interface in the $\alpha$ helix domains in subunit $\mathrm{c}$ of V-ATPase, where the formation of multiple intermolecular hydrogen bonds is less likely. ${ }^{8}$

In summary, we successfully synthesized site-specifically fluorinated bafiromycin $A_{1}$ at the $C 2$ position of the macrolactone ring. This analogue exhibits potent V-ATPase inhibitory activity, and is the first bioactive agent of the plecomacrolide family compounds in which the macrolactone core is modified as far as we know. In addition, fluorine-labeling of Baf backbone with no structural perturbation would pave the way to a better understanding of the mechanism underlying V-ATPase activity and to the development of a specific inhibitor of the enzyme. Solid-state NMR experiments are now underway in our laboratory.

\section{Acknowledgments}

We thank Prof. N. Matsumori (Kyushu University) and Dr. S. Hanashima (Osaka University) for discussions and Dr. N. Inazumi (Osaka University) for his help in NMR measurements. This work was partly supported by JST ERATO, Lipid Active Structure Project, Grant-In-Aids for Scientific Research (C) (No.15K01821) and for Scientific Research (A) (No.25242073) and Grants for Excellent Graduate Schools, MEXT, Japan. H.S. expresses his special thanks for the supports from Global COE Programs of Osaka University.

\section{Supplementary Material}

Supplementary data associated with this article can be found, in the online version, at http://

\section{References and notes}

1. M. Forgac, Nat. Rev. Mol. Cell Biol. 2007, 8, 917-929.

2. K. Cotter, L. Stransky, C. McGuire, M. Forgac, Trends Biochem. Sci. 2015, 40, 611-622.

3. V. Marshansky, J. L. Rubinstein, G. Grüber, Biochim. Biophys. Acta 2014, 1837, 857-879.

4. G.-H. Sun-Wada, Y. Wada, Biochim. Biophys. Acta 2015, 1847, 1166-1172.

5. R. M. Graham, J. W. Thompson, K. A. Webster, Oncotarget 2013, $5,1162-1173$.

6. L. S. Schneider, K. V. Schwarzenberg, T. Lehr, M. Ulrich, R. Kubisch-Dohmen, J. Liebl, D. Trauner, D. Menche, A. M. Vollmar, Cancer Res. 2015, 75, 2863-2874.

7. a) G. Werner, H. Hagenmaier, K. Albert, H. Kohlshorn, Tetrahedron Lett. 1983, 24, 5193-5196; b) G. Werner, H.
Hagenmaier, H. Drautz, A. Baumgartner, H. Zähner, J. Antibiot. 1984, 37, 110-117.

8. a) B. J. Bowman, E. J. Bowman, J. Biol. Chem. 2002, 277, 39653972; b) E. J. Bowman, L. A. Graham, T. H. Stevens, B. J. Bowman, J. Biol. Chem. 2004, 279, 33131-33138; c) B. J. Bowman, M. E. McCall, R. Baertsch, E. J. Bowman, J. Biol. Chem. 2006, 281, 31885-31893.

9. a) M. Huss, G. Ingenhorst, S. Kçnig, M. Gaßel, S. Drçse, A. Zeeck, K. Altendorf, H. Wieczorek, J. Biol. Chem. 2002, 277, 40544-40548; b) C. Osteresch, T. Bender, S. Grond, P. V. Zezschwitz, B. Kunze, R. Jansen, M. Huss, H. Wieczorek, J. Biol. Chem. 2012, 287, 31866-31876.

10. T. Gullion, J. Schaefer, J. Magn. Reson. 1989, 81, 196-200.

11. T. Gullion, Annual Reports on NMR Spectroscopy 2009, 65, 111137.

12. (a) C. Lu, Y. Shen, J. Antibiot. 2003, 56, 415-418; (b) E. Ohta, N. K. Kubota, S. Ohta, M. Suzuki, T. Ogawa, A. Yamasaki, S. Ikegami, Tetrahedron 2001, 57, 8463-8467; (c) S. Gagliardi, P. A. Gatti, P. Belfiore, A. Zocchetti, G. D. Clarke, C. Farina, J. Med. Chem. 1998, 41, 1883-1893.

13. a) H. Shibata, H. Tsuchikawa, N. Matsumori, M. Murata, T. Usui, Chem. Lett. 2014, 43, 474-476. b) H. Shibata, H. Tsuchikawa, T. Hayashi, N. Matsumori, M. Murata, T. Usui, Chem. Asian J. 2015, 10,915-924.

14. B. E. Smart, J. Fluorine Chem. 2001, 109, 3-11.

15. a) K. Toshima, T. Jyojima, H. Yamaguti, Y. Noguchi, T. Yoshida, H. Murase, M. Nakata, M. Matsumura, J. Org. Chem. 1997, 62, 3271-3284. b) Yadav, J. S.; Reddy, K. B.; Sabitha, G. Tetrahedron 2008, 64, 1971-1982.

16. V. Rauhala, M. Nevalainen, A. M. P. Koskinen, Tetrahedron 2004, 60, 9199-9204.

17. The direct alkylation of $\mathbf{7}$ or its PMB ether derivative with $i$ $\mathrm{PrMgBr}$ resulted in no reaction or only demethoxylation. On the other hand addition of the isopropenyl magnesium bromide to 7 proceeded in $82 \%$ yield, however, any of reduction conditions did not give the desired $\beta$-alcohol $\mathbf{7 b}$ as a main product.

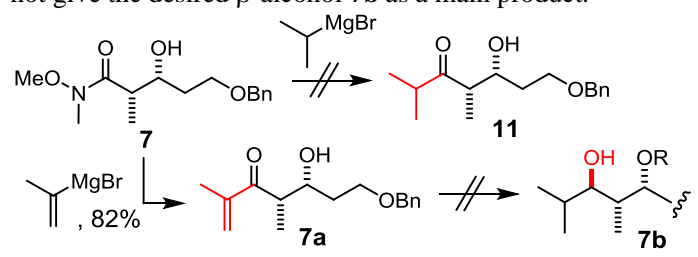

18. M. Shibuya, Y. Sasano, M. Tomizawa, T. Hamada, M. Kozawa, N. Nagahana, Y. Iwabuchi, Synthesis 2011, 3418-3425.

19. D. A. Evans, K. T. Chapman, E. M. Carreira, J. Am. Chem. Soc. 1988, 110, 3560-3578.

20. M. Michida, T. Mukaiyama, Chem. Lett. 2008, 37, 890-891.

21. J. Inanaga, K. Hirata, H. Saeki, T. Katsuki, M. Yamaguchi, Bull. Chem. Soc. Jpn. 1979, 52, 1989-1993.

22. The configuration at $\mathrm{C} 17$ and $\mathrm{C} 18$ of the major product $\mathbf{2 0}$ was determined to be the same as reported in ref. 13, see the Supporting Information for details.

23. D. A. Evans, M. A. Calter, Tetrahedron Lett. 1993, 34, 68716874.

24. When a strong acid such as TsOH was used for removal of the 7O-silyl group by following our previous synthesis, ${ }^{13}$ no deprotected product was obtained. Under acidic conditions, the lactone ring was easily opened probably due to strong inductive effect of a fluorine atom.

25. E. Uchida, Y. Ohsumi, Y. Anraku, J. Biol. Chem. 1985, 260, 1090-1095.

\section{Click here to remove instruction text...}




\section{Graphical Abstract}

To create your abstract, type over the instructions in the template box below.

Fonts or abstract dimensions should not be changed or altered.

Bafilomycin analogue site-specifically

Leave this area blank for abstract info.

fluorinated at the pharmacophore

macrolactone ring has potent vacuolar-type

ATPase inhibitory activity

Hiroshi Tsuchikawa, Tatsuru Hayashi, Hajime Shibata, Michio Murata, Yoko Nagumo, Takeo Usui<smiles>CO[C@H](/C=C/C=C(\C)C[C@H](C)C(O)C(C)/C=C(C)/C=C(\[O-])C(=O)O)C(C)[C@@H](O)[C@H](C)C1(O)CC(O)[C@@H](C)C(C(C)C)O1</smiles> 